\title{
THE TEST OF THE SUBSPECIES
}

\section{By P. A. TAVERner}

In the Journal of Mammalogy, Vol. 1, No. 1, pp. 6-9, appears an article by Dr. C. Hart Merriam advocating that the amount of differentiation be used as the test of specific or subspecific status, rather than the generally accepted one of intergradation. It is with some trepidation that I dare take direct issue with so eminent an authority but the case seems so clear against the proposal and its acceptance is so fraught with possibilities of confusion that I feel justified in lodging a protest.

Doctor Merriam makes much of the uncertainty of human judgment in estimating the probability of intergradation when direct evidence of it is lacking. For the sake of these minority cases where the human element may give varying results, he advocates the recognition of the amount of difference exhibited rather than the presence or absence of intergradation as the test for specific status; thus throwing open each and every case, instead of an occasional one, to the uncertainty of personal standards of judgment. It looks like out of the frying pan into the fire and the choosing of the greater instead of the lesser of two evils. Under the one standard we have numerous cases where intergradation can be demonstrated and subspecific status fixed. Under the other all are equally uncertain. It would seem more logical to go to the other extreme and ascribe every difference to the specific that cannot be demonstrated to intergrade with others. This would however be carrying logic to an extreme and I see no real reason why we should not continue to rely upon the good judgment of experience to assume the probability of intergradation where data is incomplete, readjusting mistakes according to new evidence. Finality can thus be gradually approached even though it may never be perfectly attained. The occasional transference of species to subspecific status and the converse are not serious disturbances so long as we keep the fundamental differentiation in mind and remember that in many cases intergradation is hypothetical and still awaits demonstration.

It is also more than probable that a strict adherence to the proposed criterion would land us in greater confusion than we experience now. Under it, on the evidence of specimens on which most of our conclusions are based, we would class the gray-cheeked and olive-backed thrushes as mere subspecies whilst the extremes of such forms as song sparrows, fox sparrows and horned larks we would raise to full specific status. 
It is beside the question that in some particular cases such a proceeding might conceivably be an advantage for it is recognized that extremes of obvious subspecies sometimes differ more in apparent characters than do other distinct species. It is thus apparent I think, from the standpoint of mere expediency, that the amount of divergence as a test of the lower systematic units is open to serious question.

The only logical ground for applying a quantitative rather than an intergradational test to the subspecies is that of the instability of species. If species are liquid quantities flowing imperceptibly into each other the amount of difference by which they are characterized is the only practical means for their recognition. If, however, the species is a definite entity it must be cut off sharply from all other similar entities and degree of divergence becomes unimportant and isolation (discontinuity) its final test. Herein lies a conflict of ideas.

Those who concentrate their attention on the paleontological evidence are prone to regard the species as a mere concept, an ever varying quantity in constant state of development, adopted for convenience in referring to arbitrary points along a continuous line of progress. The modern zoologist however finds species the termination of lines of descent, and each sharply marked off from the other. As both of these reasonings are demonstrable it is apparent that in the word "species," as generally accepted, we have lumped two separate concepts. Certainly contemporaneous and consecutive species bear fundamentally different relations to each other and between themselves, and eventually will probably have to be differentiated by systematists. It is only the fragmentary nature of our geological evidence that has heretofore concealed the essential difference between species merging into each other along a line of descent and species the outcome of independent lines of descent. Intergradation is a concomitant of the first but incompatible with the latter.

It can be urged that evolution is an always present activity, that the processes of the past are continuing in the present and any system founded upon the stability of the species is doomed to eventual confusion. This may be correct philosophically, but in practice need hardly be considered in dealing with modern material. Within historical times we have absolutely no evidence of serious evolutionary change. A system that would have sufficed for three thousand years in the past will probably do for an equal time in the future. By the time evolutionary change introduces serious disturbance in the present scheme of things it is probable that our whole classification system will have been 
scrapped for something better or else altered beyond recognition. In the meantime I think we are safe in basing our working system on the convention that existing relationships are practically stable.

Though all standards of taxonomic measurement are not mutually transferable between paleontology and modern zoology it does not follow that paleontological evidence should be neglected by modern systematists. As its evidence increases and its lessons become plainer, paleontology must be, even more in the future than it has been in the past, the rule and guide of our classification. We should however bear in mind that concepts that apply to the one may require modification before they can be transferred to the other.

However otherwise it may have been in the past or may be in the future, at the present moment or on any one given geological horizon, the species is a definite entity and its essential character is its genetic isolation. Absence of intergradation with other forms is the only test of the species as it exists at present. There is a barrier that isolates modern specific groups one from another, individualizes contemporary species and prevents wholesale mongrelization. Just what this barrier may be we cannot say with confidence, nor is it altogether necessary to the present argument to do so, but the agent that seems most capable of producing present results is the degree of fertility between such groups. When fertility between divergent forms breaks down, when differentiation progresses to the reproductive processes sufficiently to form a handicap to crossbreeding, genetic isolation ensues that forever separates the varying branches of a common stock and a new species is born. Whatever the mechanics may be that tend to hold a species true and prevents promiscuity, subspecies are incipient species, and I do not see what they can be but variations tending towards, but not reaching, specific status until connection with other forms (intergradation) is broken down and isolation established. Thus intergradation is not only an indication of a condition but it is the condition itself and the refusal to recognize it as the essential quality of the subspecies seems to be a denial of fact. It should be admitted, and can be without discrediting the fundamental argument, that intergrades will not always be discovered. Material from critical localities may not be available or connecting distributions may be obliterated through geographical or ecological changes. Subspecific variations may appear in disconnected communities and give rise to discontinuous distribution where even intergradation through individual variation may conceivably be obscured. without in any way denying the relative status of 
the forms concerned. The accidental absence of intergrades in these cases complicates the demonstration but cannot alter the fundamental facts. No system of classification has ever entirely done away with the necessity of exercising some judgment and probably none ever will, and the best we can arrive at is to reduce the human equation to its lowest possible terms consistent with the facts of nature. The possibility of intergradation where contact between races is physically impossible must necessarily be estimated under the guidance of what evidence we have. The test of intergradation or its possibility where physically prevented gives a far more definite basis of judgment than unmeasurable generalities expressed as vague comparatives of difference. That such proceeding does in practice and in some cases, approximate the criterion laid down by Doctor Merriam is beside the point as the resemblance is superficial and not fundamental. In one case it is frankly an expedient, a suggestion or means to an end, in the other it is the end itself and final.

In this argument I do not forget such cases as the hybrid flicker nor Lawrence's and Brewster's warblers. These if anything substantiate the view that degrees of sterility form the specific boundary lines. That the parent forms of these anomalies are not mongrelized is evidence that such cross breeding is under a handicap as against purer lines of descent; for it is a mere matter of mathematics to prove that otherwise species that hybridize regularly, even if only occasionally, would eventually merge. I have little doubt that the hybrid flicker which shows no appreciable evidence of sterility is only continued through fresh crossings of original stock and that should either parent form be exterminated, it would in a few generations die out through inherent weakness and inability to compete with either of its more virile parent forms.

Therefore, for reasons of both expediency and philosophy, stability of nomenclature and the teachings of evolution, I respectfully submit that the fact of intergradation is the only proper and workable test of subspecific status and should be firmly held to by all students of speciation. 


\section{$2 \mathrm{BHL}$ Biodiversity Heritage Library}

Taverner, P. A. 1920. "The Test of the Subspecies." Journal of mammalogy 1 , 124-127. https://doi.org/10.2307/1373336.

View This Item Online: https://www.biodiversitylibrary.org/item/220052

DOI: https://doi.org/10.2307/1373336

Permalink: https://www.biodiversitylibrary.org/partpdf/90500

\section{Holding Institution}

Smithsonian Libraries

\section{Sponsored by}

Biodiversity Heritage Library

\section{Copyright \& Reuse}

Copyright Status: Not in copyright. The BHL knows of no copyright restrictions on this item.

This document was created from content at the Biodiversity Heritage Library, the world's largest open access digital library for biodiversity literature and archives. Visit BHL at https://www.biodiversitylibrary.org. 